\title{
Additive Construction with Mobile Emplacement (ACME) / Automated Construction of Expeditionary Structures (ACES) Materials Delivery System (MDS)
}

\author{
R. P. Mueller ${ }^{1}$, I. I. Townsend ${ }^{2}$, G. J. Tamasy ${ }^{1}$, C. J. Evers ${ }^{1}$, L. J. Sibille ${ }^{3}$, J. E. \\ Edmunson $^{4}$, M. R. Fiske ${ }^{4}$, J. C. Fikes ${ }^{5}$, M. Case ${ }^{6}$
}

\begin{abstract}
${ }^{1}$ Swamp Works Laboratory, NASA Kennedy Space Center (KSC), Mail Stop: UB-R1, Kennedy Space Center, FL 32899; email:Rob.Mueller@nasa.gov

${ }^{2}$ Craig Technologies Inc. serving Swamp Works Laboratory, NASA KSC, FL 32899; email: Ivan.I.Townsend@nasa.gov

${ }^{3}$ Ascentech Enterprises Inc. serving Swamp Works Laboratory, NASA KSC, FL 32899; email: laurent.sibille-1@nasa.gov

${ }^{4}$ Jacobs Technology Inc. serving National Aeronautics and Space Administration (NASA) Marshall Space Flight Center (MSFC), 1500 Perimeter Parkway, $4^{\text {th }}$ Floor, Huntsville, AL 35806; PH (256) 544-0721; email: Jennifer.E.Edmunson@nasa.gov, Michael.R.Fiske@nasa.gov

${ }^{5}$ NASA MSFC, ST23, Huntsville, AL 35812; email John.Fikes@nasa.gov ${ }^{6}$ USACE Construction Engineering Research Laboratory, Champaign, IL michael.p.case@usace.army.mil
\end{abstract}

\begin{abstract}
The purpose of the Automated Construction of Expeditionary Structures, Phase 3 (ACES 3) project is to incorporate the Liquid Goods Delivery System (LGDS) into the Dry Goods Delivery System (DGDS) structure to create an integrated and automated Materials Delivery System (MDS) for 3D printing structures with ordinary Portland cement (OPC) concrete. ACES 3 is a prototype for 3-D printing barracks for soldiers in forward bases, here on Earth. The LGDS supports ACES 3 by storing liquid materials, mixing recipe batches of liquid materials, and working with the Dry Goods Feed System (DGFS) previously developed for ACES 2, combining the materials that are eventually extruded out of the print nozzle. Automated Construction of Expeditionary Structures, Phase 3 (ACES 3) is a project led by the US Army Corps of Engineers (USACE) and supported by NASA. The equivalent 3D printing system for construction in space is designated Additive Construction with Mobile Emplacement (ACME) by NASA.
\end{abstract}




\section{INTRODUCTION}

This paper reviews the requirements, design, fabrication and verification \& validation testing of an automated materials delivery system (MDS) terrestrial prototype that stores, transfers, and meters all materials required to make ordinary Portland cement (OPC) concrete. The MDS in combination with a mobile concrete mixing hopper, a concrete pump, a 3D print head robotic gantry positioning system, and a 3D print head comprises a system called the Continuous Feedstock Mixing Delivery Subsystem (CFDMS) which will 3D print free standing concrete structures on Earth as well as eventually on extra-terrestrial surfaces. The Earth based prototype version is currently being used by the United States Army Corps of Engineers (USACE) to automatically print barracks for their troops with some soldier support for deployment, monitoring and maintenance. This technology will allow the USACE to create housing for troops faster than currently possible, use less manpower, improve thermal efficiency and improve ballistic protection over the current wooden structures being used. NASA's interest in this technology is to autonomously print habitats on the Moon and on Mars.



Fig. 1. Concept for a robot engaged in 3D structural printing of a habitat on the Moon

The NASA ACME project (Mueller, 2017) is a joint venture between NASA's Space Technology Mission Directorate (STMD) Game Changing Development (GCD) Program and the United States Army Corps of Engineers (USACE) Engineer Research and Development Center - Construction Engineering Research Laboratory (ERDCCERL) with Marshall Space Flight Center and Kennedy Space Center as partners in project execution. Other partners included the Contour Crafting Corporation and the Pacific International Space Center for Exploration Systems (PISCES) as well as various engineering and fabrication support contractors.

The purpose of the ACME project was to research and develop additive construction technologies at a relevant scale capable of achieving the goals of both USACE and 
NASA. The project served NASA's long-term goal of reducing launch mass for deep space human missions by enabling spaceflight crews to 3D print needed regolith structures on demand by using local materials, and transmitting building and other structural/civil engineering designs in three dimensional (3D) computer Aided Design (CAD) digital format from Earth to maximize system adaptability and mission assurance.

Autonomous construction of free standing structures requires a set of sub-systems that communicate seamlessly with each other. These systems begin with mobility bases that autonomously deliver the required bulk granular and liquid material to the MDS hoppers. The MDS delivers metered amounts of dry and liquid materials to a mobile hopper where the material is mixed and delivered to a concrete pump. The materials are then transferred via a hose to a 3D print head that is guided by the 3D Print Head Positioning Device (3D-PHPD). This paper describes the MDS system requirements, design, fabrication, and testing efforts.

\section{PROJECT OBJECTIVES (ACME)}

The combination of the objectives of both customers of the project, namely the USACE and NASA created a high degree of synergy of resources and cross-pollination of ideas and skills between the project team members and the stakeholders. Many objectives of USACE and NASA overlap in their philosophy while the differing objectives were such that they could be pursued independently without compromising the common approach adopted for the realization of the core hardware. This project synergy was built in the initial project design through extensive discussions between stakeholders, project managers and engineers.

The USACE had the following objectives for construction of a B-hut in a forward base:

- Reduce construction time

- Reduce construction personnel requirements

- Reduced logistics impacts associated with materials shipped, personnel, and resources to sustain the structures and personnel

- Decrease material shipped from "out of theater"

- Improved energy performance of the envelope

- Reduced sustainment (logistics) and operations/maintenance personnel

- Reduce construction waste

- Improved security during construction

- Improved local population acceptance by mimicking local construction

NASA had the following objectives for construction of a prototype habitat for feasibility and potential astronaut crew training:

- First demonstration of additive construction using planetary analog materials

- Provide a detailed analysis of materials for additive construction on different planets, including radiation shielding potential 
- Advance the Technology Readiness Level (TRL) of additive construction hardware and processes to provide risk reduction and capabilities to future mission development programs

- Provide the gateway to fabricating structures on demand in space with in-situ resources, reducing the need for sizeable structure up-mass

- Provide a significant return on investment by enabling future NASA missions not feasible without the capability to manufacture structures in-situ and doing so with significant external leverage

- Provide a first step towards evolving 3D autonomous additive construction (3DAAC) for use on Deep Space Missions

- Demonstrate tele-operations to reduce costs of testing operations on Earth and show applicability to planetary surfaces

\section{SYSTEM ARCHITECTURE (ACME)}

The arrival of a human crew on Mars will be a major milestone on the path of human history. While it will represent a remarkable achievement in space transportation and logistics, it will also herald a new era defined by crews becoming more independent in their capabilities and decision-making. The multi-months duration and energy constraints of the journey between Earth and Mars are forcing this evolution toward self-sufficiency that will enable crews to adapt to changing circumstances and survive emergencies so far from Earth.

Shelter is one of the primary needs of humans and the environment of planetary surfaces such as Mars and the Earth's moon also requires protection for critical surface equipment on which human crews will rely; robotic transporter rovers, cranes, processing plants for consumable production are examples of hardware that could be damaged by large thermal swings, weather, solar particle events (SPEs), Galactic Cosmic Rays (GCR), meteorite bombardment, rocket engine blast ejecta and dust storms, potentially crippling the human mission.

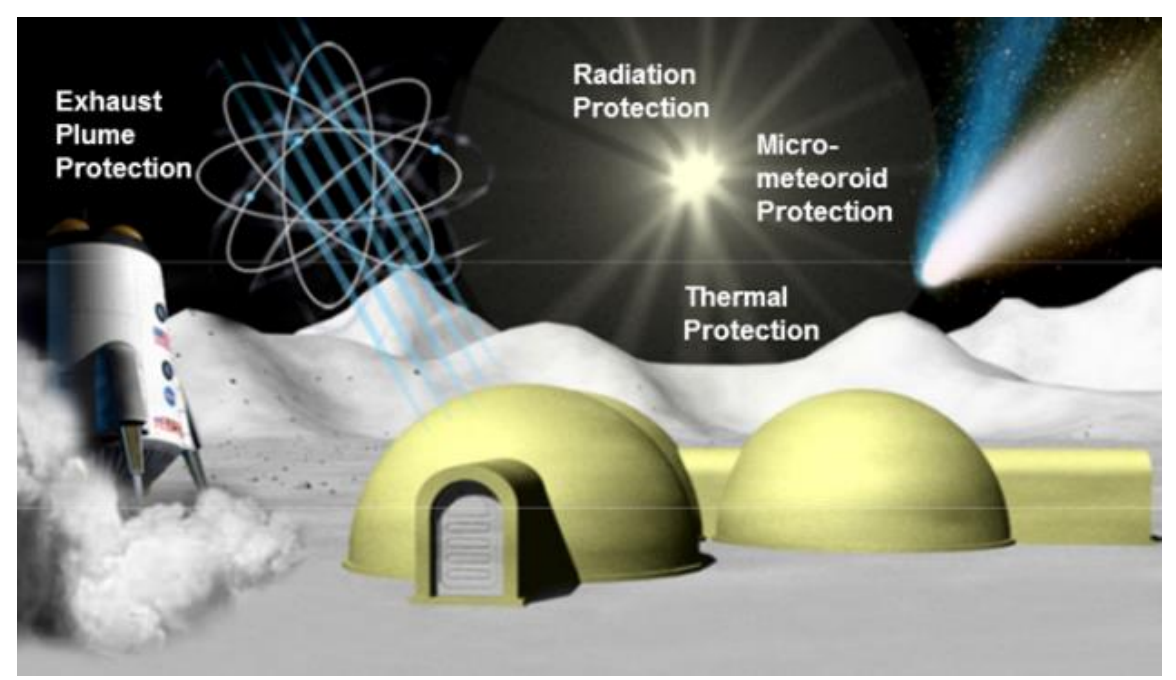

Fig. 2. Shelter from the deep space surface environment is the top goal for ACME technology development 
Several other types of structures are considered to be potential enabling elements in a Mars surface architecture for human missions. These include constructed landing/liftoff pads for spacecraft, protective berms and walls around such landing/lift-off zones to protect other elements from ejecta generated by engine gas plumes.

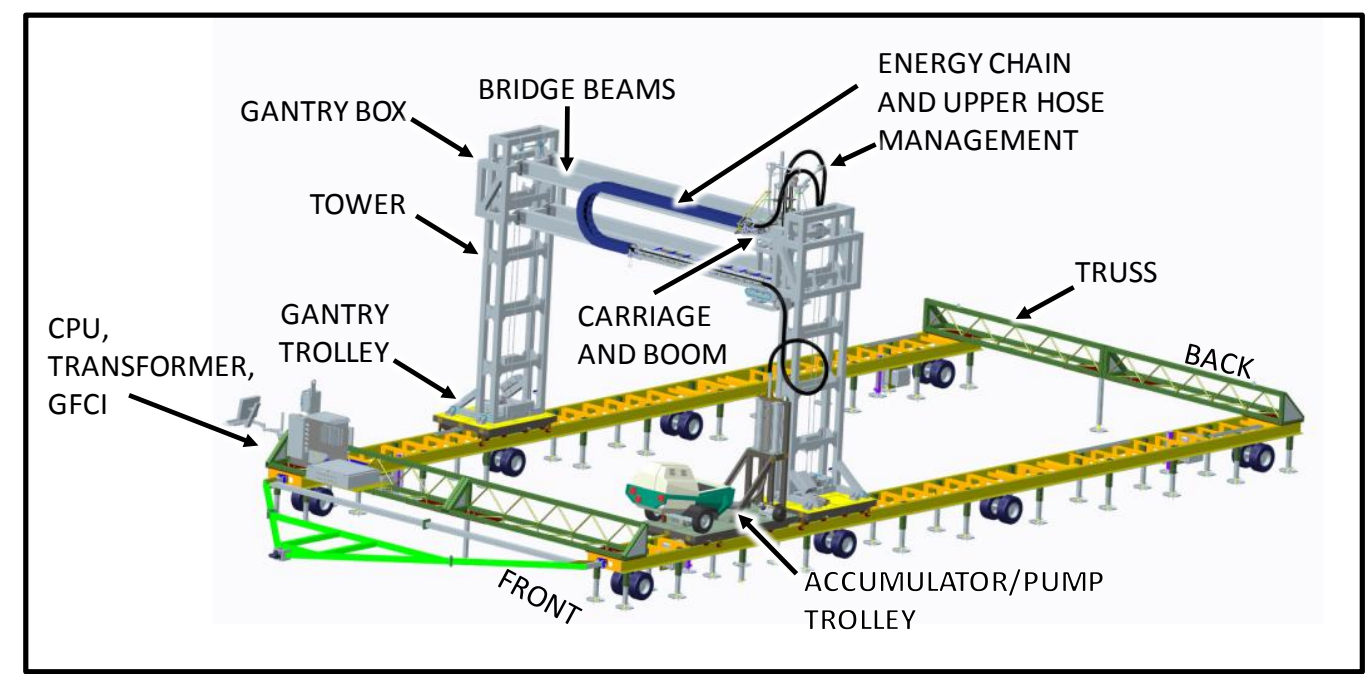

Fig. 3. Design model of ACES-3 automated additive construction system

The robotic gantry system design that was developed for ACES-3 is shown in Figure 3 and shows the concrete slurry print head positioning system elements. The actual hardware that was subsequently fabricated by NASA MSFC is shown in Figure 4.

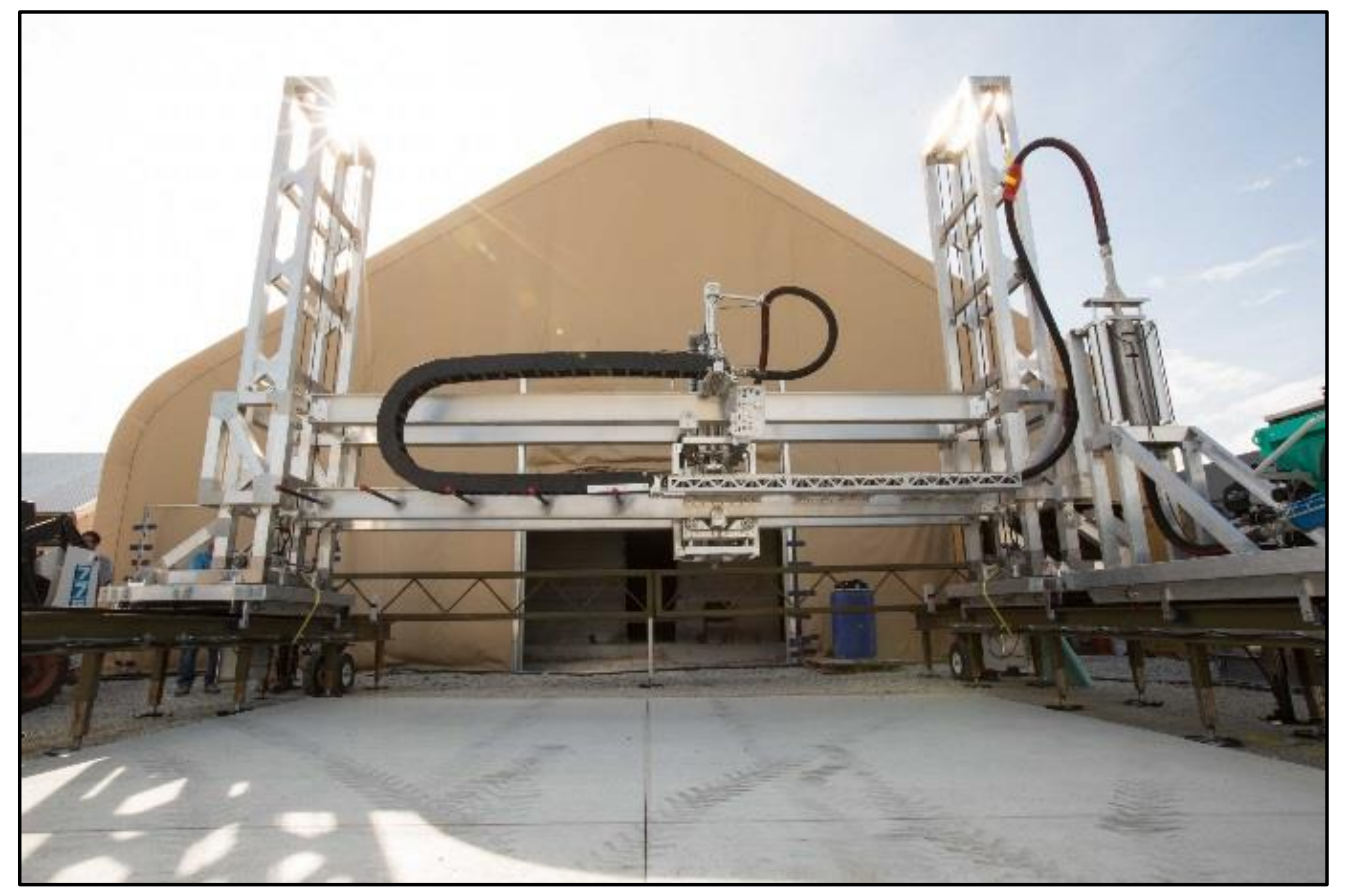

Fig. 4. ACES-3 Automated Additive Construction System: As-Built 
In order to provide experience and inform the ACES-3 design a previous version, ACES- 2 was designed and fabricated by ERDC-CERL. This prototype was effective in the 3D printing construction of a concrete Barracks (B)-Hut, the first habitat structure ever 3D printed with OPC concrete using $3 / 8$ inch aggregate for higher strength concrete. The successful demonstration is shown in Figure 5, and has provided a good knowledge base of the ACES-3 iteration.

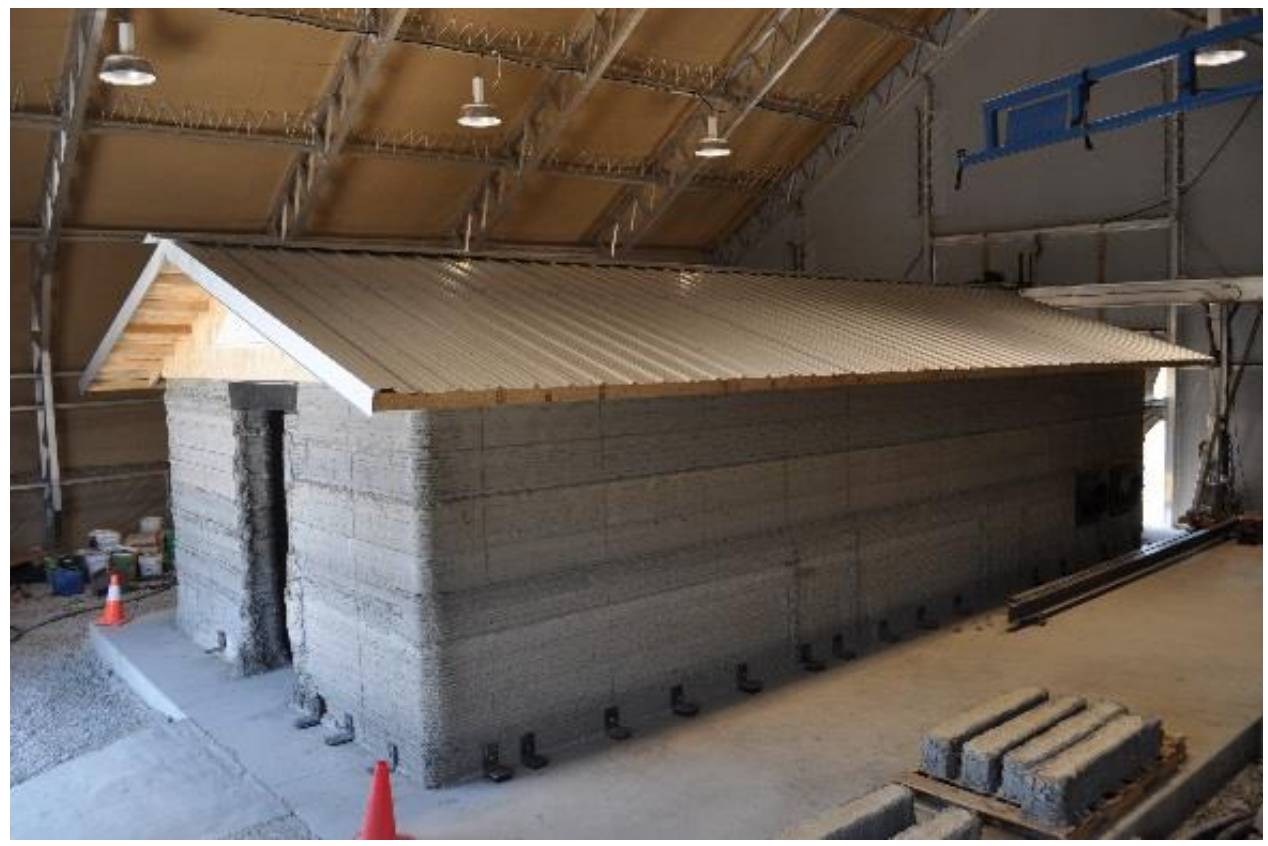

Fig. 5. Completed ACES-2 3D Printed B-Hut Prototype Wall Structure

\section{MDS DEVELOPMENT}

The MDS consists of an integrated DGDS and LGDS that can automatically dispense the dry and liquid ingredients that make up the OPC specially formulated concrete recipe, which is suitable for $3 \mathrm{D}$ printing extrusion through a print head with appropriate rheology and curing characteristics. Seven (7) dry material hoppers, eight (8) auger feed systems, one (1) weigh hopper, and a control system make up what is designated as the Dry Goods Delivery System (DGDS). The system that delivers liquid commodities is called the Liquid Goods Delivery System (LGDS) and consists of five (5) storage tanks, associated valves, and a control system. These rae both integrated into a steel structural frame that is designed to be transportable (while empty) on a flatbed truck or a C-130 military transport aircraft. It weighs approximately 11,000 pounds $(4990 \mathrm{~kg}$ ) when empty. 


\section{ACES-3 Automated Additive Construction System}

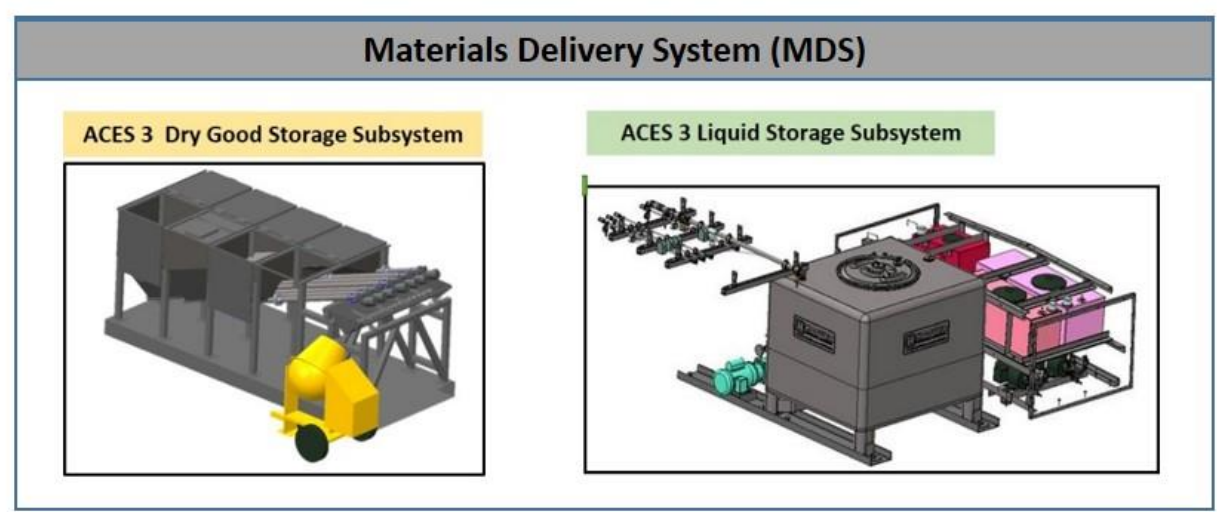

\section{Continuous Feedstock Mixing Delivery Subsystem (CFDMS)}

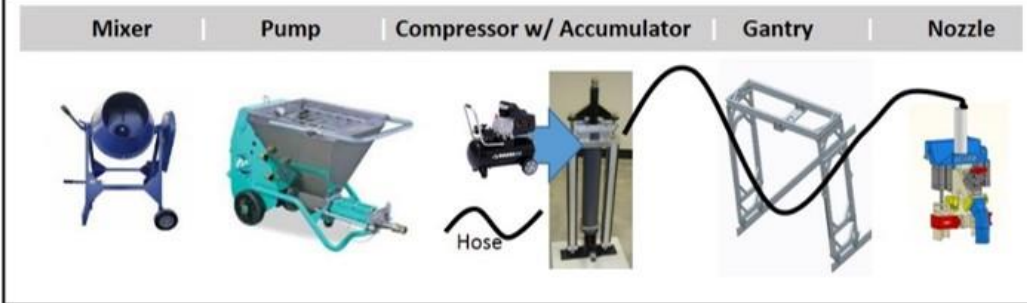

Figure 6. Showing the CFDMS System.

The DGDS delivers all ingredients into a separate weigh hopper that has four (4) load cells which can accurately weigh the dispensed dry goods before augering them into a portable concrete mixing machine hopper. The dry goods in the weigh hopper are shown in Figure 7. The MDS is a critical part of the ACES-3 system; without a suitable OPC concrete slurry material, it cannot be pumped or deposited in stacked layers. In addition the work flow must be well integrated so that the timing is synchronized with the rest of the operations and the print head can never be starved of feedstock concrete. 


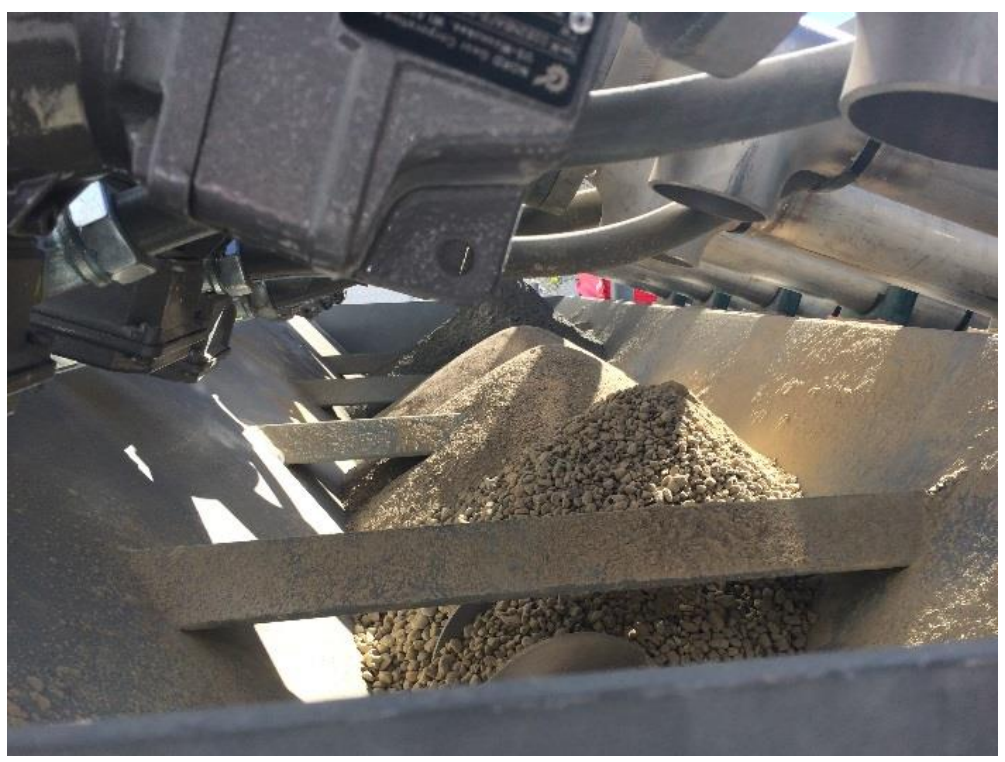

Fig. 7. Dry goods in MDS Weigh Hopper

\section{DGDS HARDWARE DEVELOPMENT}

The DGDS was designed to be a mobile, field deployable machine and was completed in phase one of the project. The major components of the DGFS include the structure, hoppers, augers, and transportation/handling features.

The structure of the DGDS consists of a framework of Hollow Structural Steel (HSS) to which the hopper panels and auger supports are welded. These sit on top of a Wbeam transport skid with forklift pockets, and tie down shackles. The structure with fully loaded hoppers was designed for transportation loads and factor of safety per NASA STD 5005D. The entire structure is coated with inorganic zinc paint for corrosion protection. The hoppers are designed to hold and store the 7 different dry materials. They are weather proof with sliding lids except for the Portland cement which has a water tight sealed top and fill-hatch. They were sized based on customer requirements to supply enough materials to complete $1 / 3$ of a concrete printed B-hut.

The hopper sides are sloped such that the dry materials flow to the auger openings in the bottom. Vibrators and air agitator are provided to aid in the movement of powdery and wet sand materials that do not naturally flow by gravity alone. Each hopper is labeled with a stencil on its side and lid with the material that it contains. 


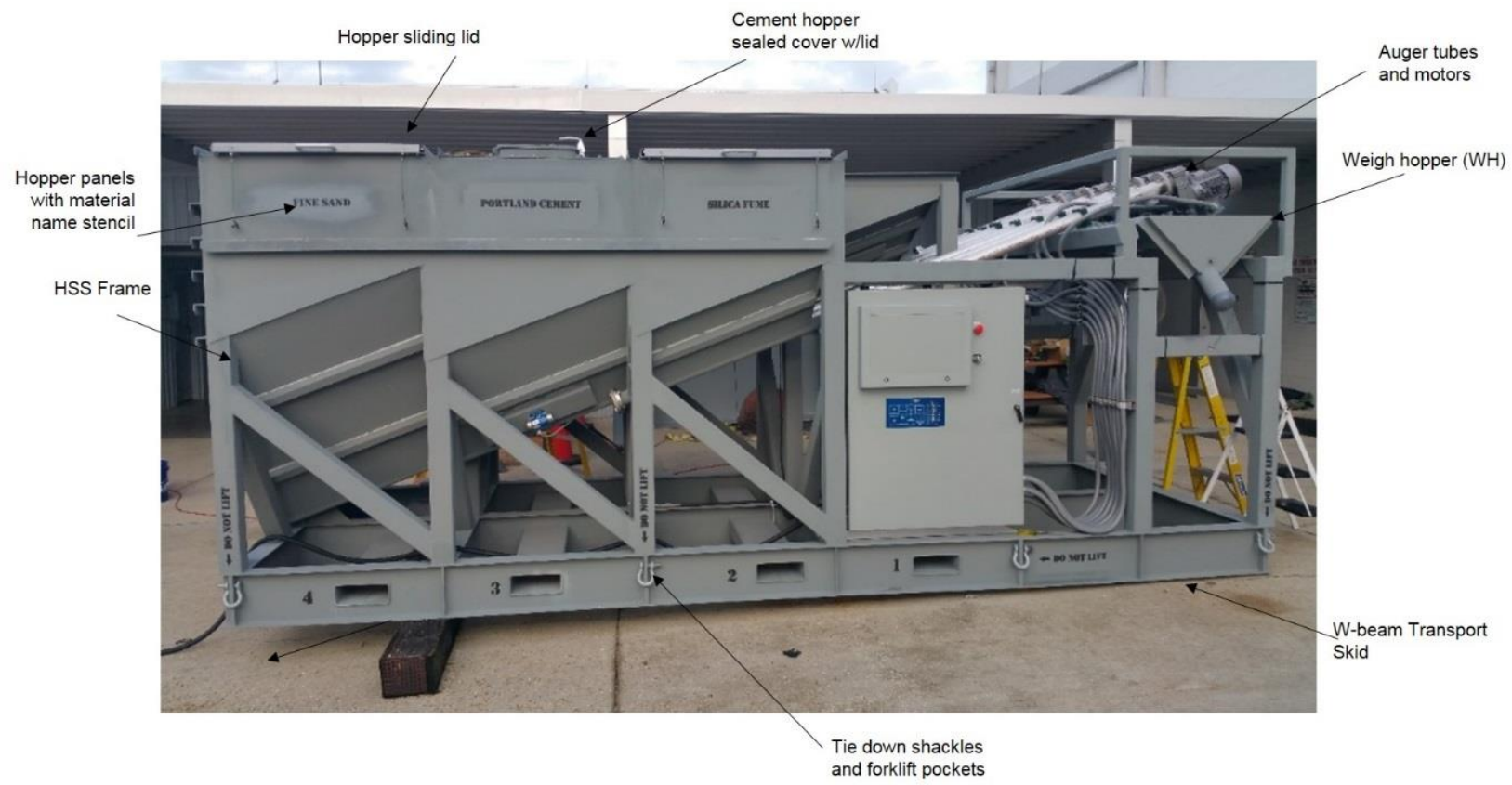

Fig. 9. DGDS Structure and Components

There are 7 augers (6 material hopper, $1 \mathrm{WH}$ ) that move the materials from the hoppers into an external cement mixer. The 6 material augers are flexible spiral and rotate inside pipes. They deliver material in a pre-programed sequence to the weigh hopper (WH). The desired mixture is measured by weight by the WH load cells and once the recipe is complete the $\mathrm{WH}$ auger moves the material to the discharge tube. The auger motors are controlled by VFD (variable frequency drives) for precise stop/start and speed control. Each material has unique flow characteristics and the augers are tuned to move the materials in the most efficient way possible. Transport and handling is a major design feature of the MDS. There are numerous ways the machine can be moved and transported. There are forklift pockets and tie down shackles so it can be forklifted onto and secured on a flatbed truck. There is a hook latch and rear roles to be moved with an ARMY Palletized Load System (PLS) truck and trailer. The MDS can also be crane lifted and has lifting shackles as shown in the figures below.

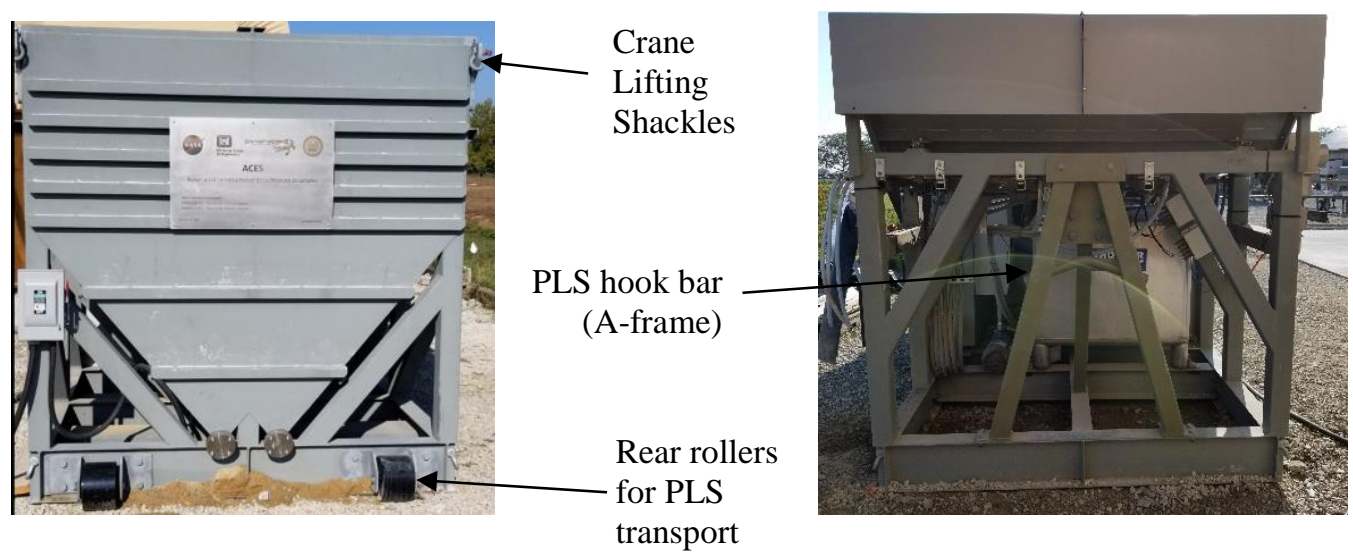

Fig. 10. Showing the front and back ends of the MDS. 


\section{LGDS HARDWARE DEVELOPMENT}

The second phase of the project was to add-on the Liquid Goods Delivery System (LGDS). This capability enables the MDS to deliver the complete mixture of materials needed to make the concrete. The LGDS consists of tanks, pumps, piping, and metering components to deliver up to 5 liquid commodities, but currently only 4 are used and 1 is a spare for future use. The liquid commodities currently used are water, accelerator, rheology controller, and plasticizer.

Each tank is positioned for ease of filling/draining and servicing. The additives tanks are housed in a weather proof heated enclosure to allow cold weather operation. Some of the additives cannot drop below $34^{\circ} \mathrm{F}$ so a thermostat controlled heater is provided to keep the additives within their required temperature range. Each tank is equipped with a level sensor and temperature sensor used by the control system to monitor the condition of the tanks and alert the user if refilling of heating is required.
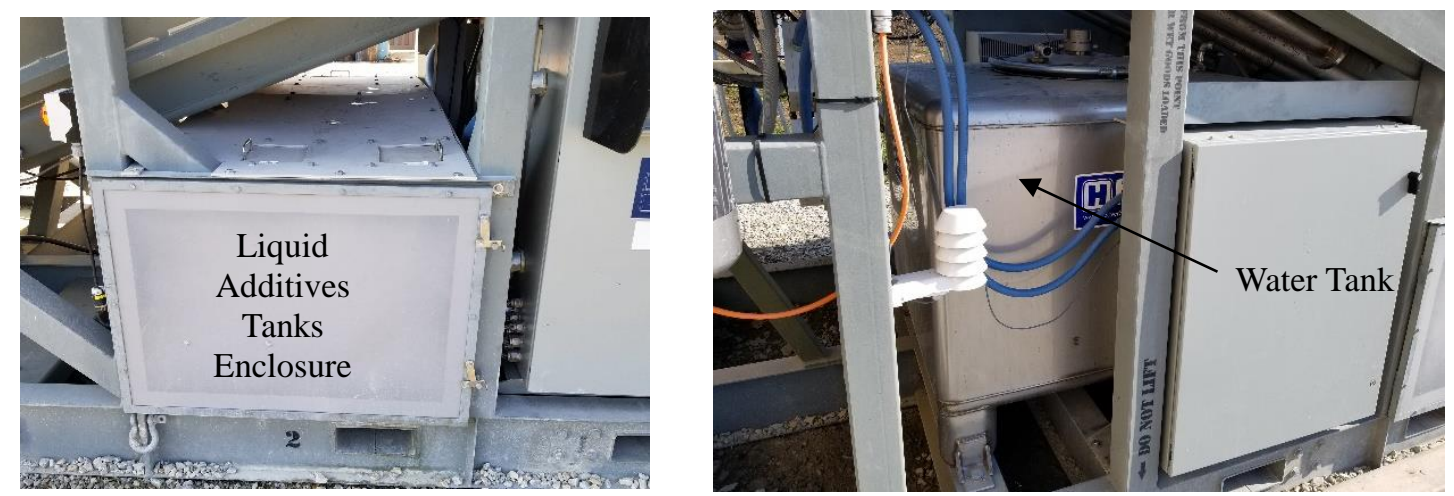

Fig. 11. Showing the LGDS storage tanks

The LGDS has two types of pumps. For the 4 additives some of which are quite viscous and relatively small volumes are required then gear pumps are used. The water pump is a self-priming centrifugal impeller pump.


Fig. 12. Showing the LGDS Pumps and Fluid Lines 
The liquid goods are transferred through flexible piping and each pump has a pressure relief valve to protect the piping and components from over pressure. Each line has a flow meter and solenoid control valve connected to the control system to dispense precise amounts of liquids. The exit of the liquid pipes is next to the dry goods weigh hopper discharge where they can flow directly into the cement mixer as the dry good are dispensed. Check valves at the exit of each liquid pipe shut off the flow when the pumps are stopped.
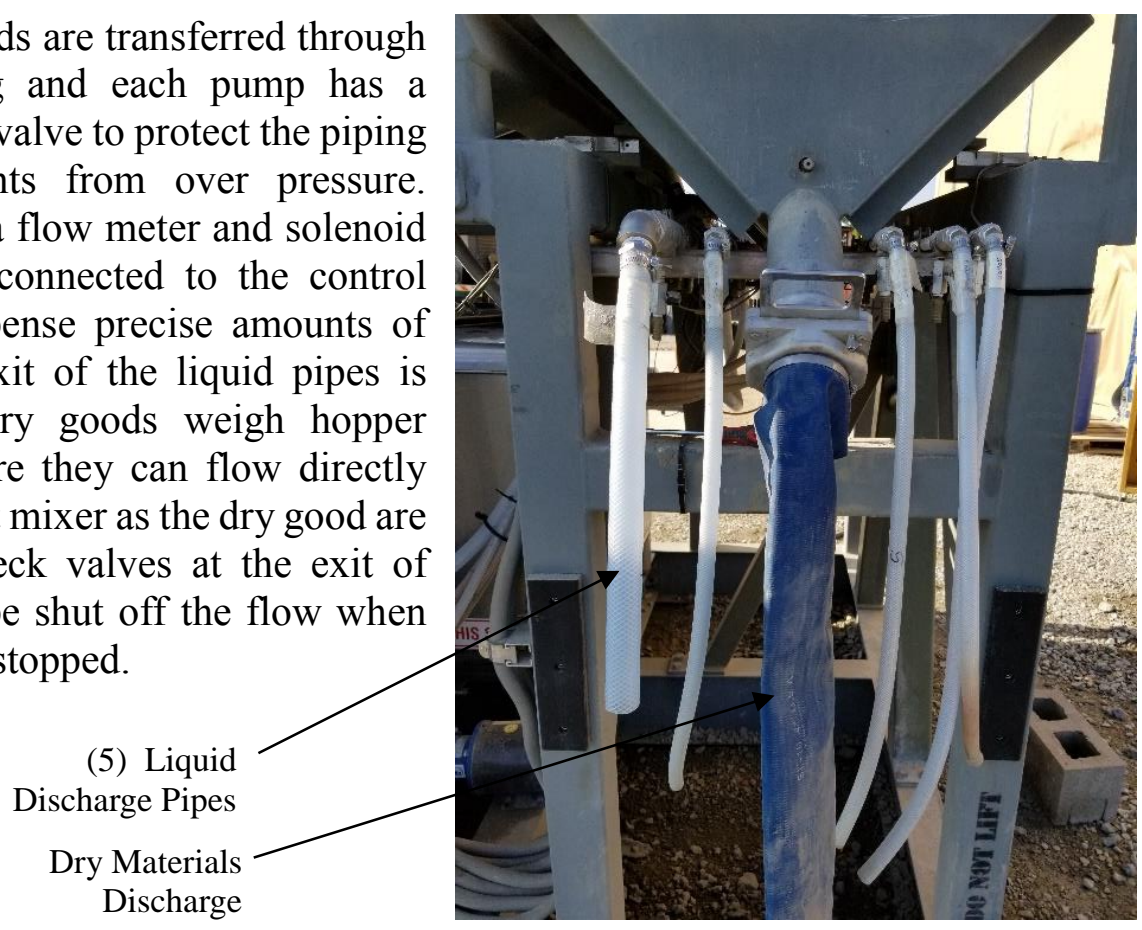

Fig. 13. Showing the LGDS Liquid Discharge Hoses Interface

\section{MDS SOFTWARE DEVELOPMENT}

A control system containing LabVIEW software that is integrated with the ACES2 software is planned to be delivered with the ACME ACES3 LGDS. This SRDS document contains software requirements, software design details, software requirement verification \& validation plan, software requirement traceability and verification matrix, and software test plan for the ACES3 LabVIEW software package.

\section{SOFTWARE REQUIREMENTS:}

\begin{tabular}{l}
\hline Requirement Description: \\
\hline LGDS subsystem shall have the capability of independent control. \\
LGDS shall have local control with an interface for higher subsystem \\
automation. \\
\hline LGDS controller shall provide data to a data recorder. \\
\hline LGDS shall meter liquids by volume, with error that will not exceed +/-3 \\
percent. \\
LGDS shall be designed to deliver 5 discrete liquids to the mixer. \\
LGDS shall have local control with an interface for higher subsystem \\
automation.
\end{tabular}

Table 2. Showing ACES III High Level Requirements 
To reduce time and cost in the software design development and implementation of the LGDS, the LGDS software was developed to an Embedded User Interface (UI) feature on the cRIO-9030. The use of the Embedded UI feature grants the following capabilities:

- Removes the need for a dedicated HMI, reducing overall system complexity and cost

- Provides the ability to reuse and display the front panel of the Labview RT VI

- Allows user event programming for front panel objects

OPERATION:

The MDS can be ran in manual mode, semi-automatic or automatic mode. The manual, semi-automatic mode, and fully automatic mode. Fully-Auto allows the operator to create and select from several batch recipes.

The Control tabs allow the user to operate the LGDS in Manual, Semi-Auto, and FullyAuto modes.

- Manual Motor Control allows full control of all motors in the system

- Semi-Auto allows the operator to add a commodity by volume in gallons for LGDS (by weight in pounds for DGFS).

- Fully-Auto allows the operator to create and select from several batch recipes.

Monitoring Tabs open to show all of the flow rates, volume and motor states. cRIO health and status is available to the user as well.

\section{$\mathrm{HMI}$ - Front Panel}

The front panel of the HMI.vi will be used as the display on the Touch Panel Monitor. For the UI, tab control is the method that was used in DGFS to organize and display information that cannot fit on one screen, this will be continued as LGDS is developed and integrated. The UI is primarily divided into two main sections - Control and Monitoring.

HMI - Block Diagram

The block diagram code consists of four asynchronous loops that communicate with each other using queues and Single Process RT Variables. 


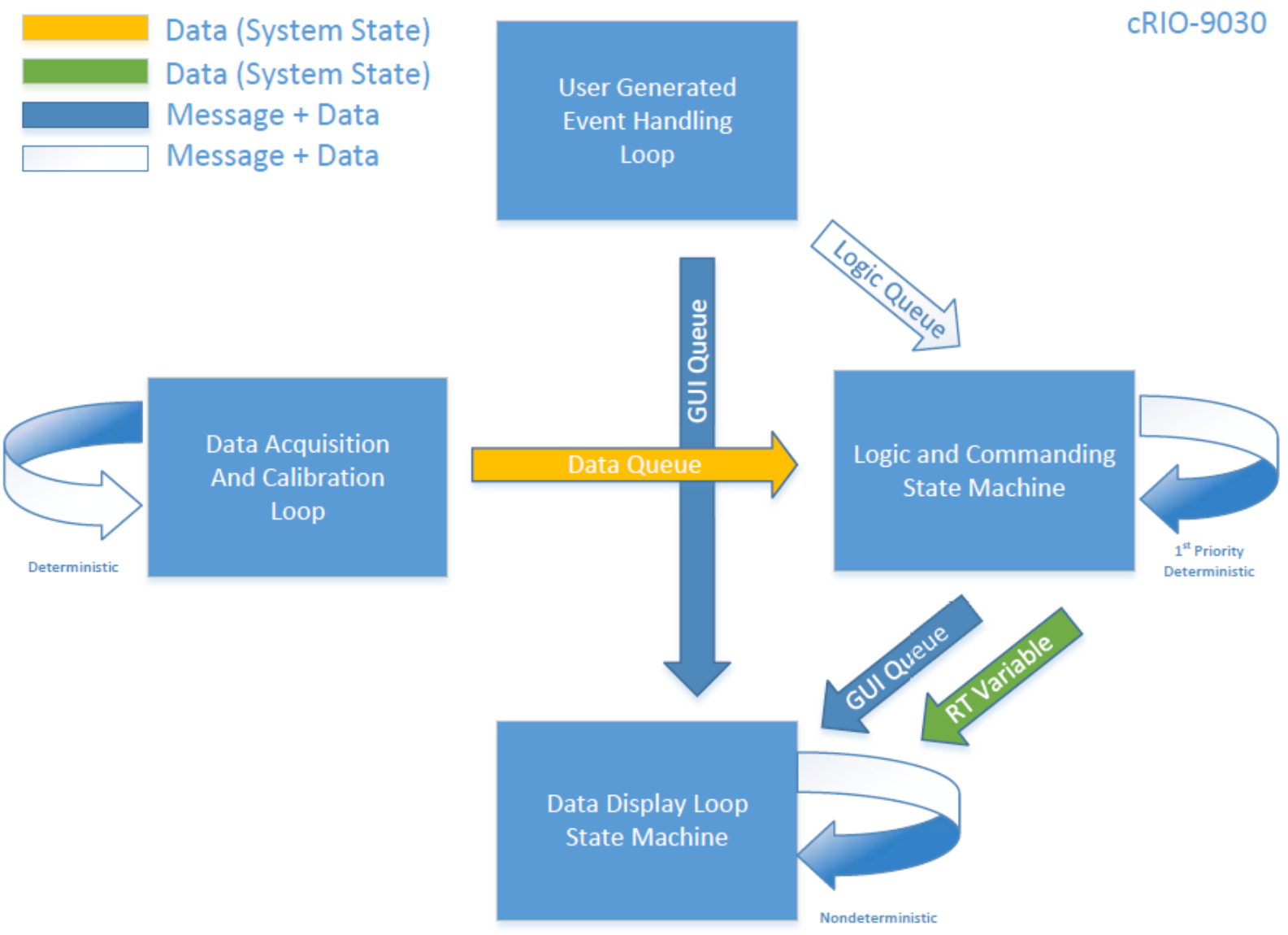

Figure 14. Showing the Acquisition Loop (Timed Loop that can be changed real time by the user) - Acquires the data using the

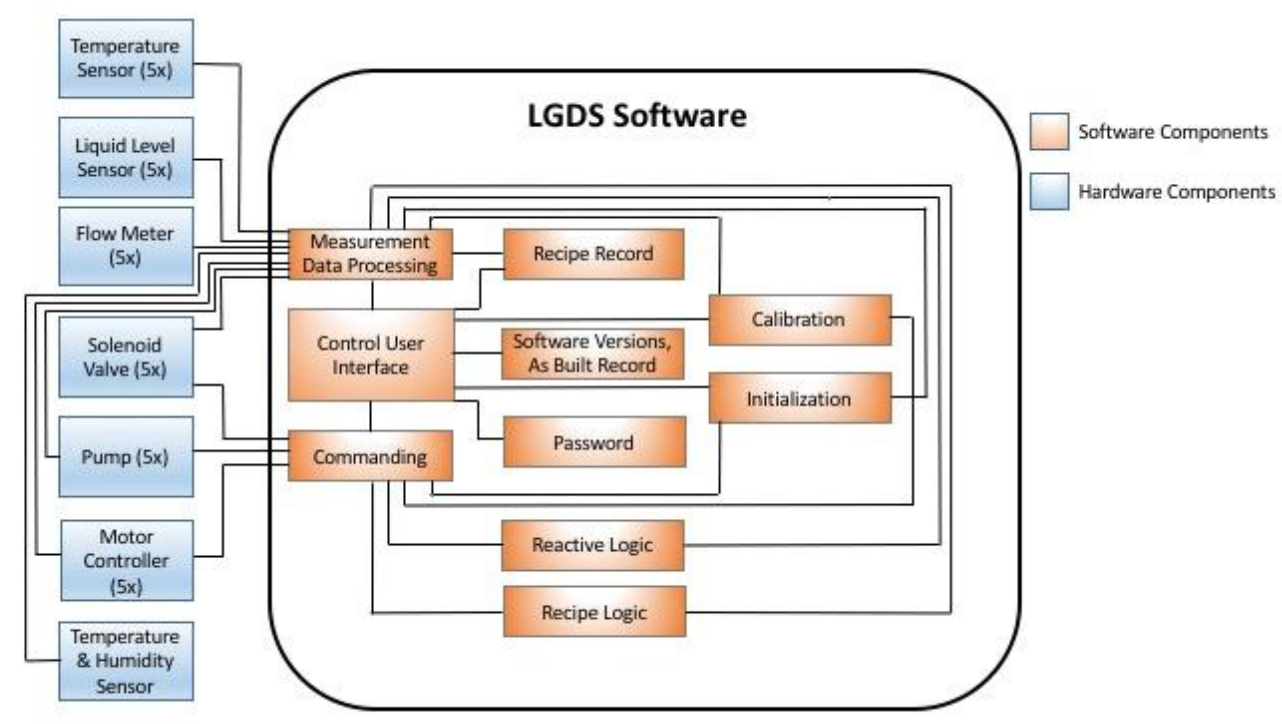

Figure 15. Showing a block diagram of the LGDS software components, with the associated LabVIEW 


\section{MDS TESTING}

Testing was a necessary and integral part of the design and development process of this system especially the DGDS. Due to the nature of the dry granular materials, it is not possible to accurately model and calculate the flow and transport behavior of the materials, so testing was essential and was used to check the hopper geometry, size the motors and augers, and to validate the flow rate performance of each material. During initial concept designs, mock ups were built to test different concepts for feeding and weighing the dry materials. Concepts like vibratory slot feeders and open belt conveyors were tested. Also closed pipe with auger transport and continuous weighing of the material in the pipe was tested. Though a down select testing process the concepts were narrowed down to the final design. Hopper geometry was largely driven by the customer requirements for the volume of material and overall machine size, but tests with wooden mock ups to evaluate angle of repose and flow characteristics of different materials. The augers were supplied by a commercial vendor specializing in auger manufacturing. We supplied the material flow rate and the hopper geometry (tube diameter, angle and length) requirements and the vendor conducted months of testing to select the best auger/motor combination for each material. Pea gravel (3/8 inch) was one of the most challenging materials to transfer with the auger due to its tendency to jam in the auger tube. For this reason a larger motor was selected for the gravel and a support bearing at the end of the auger was also provided.

During functional check out and testing each commodity was functionally tested and adjustments were made to meet the flow requirements. For the sand (largest hoppers) the auger openings needed to be reduced in size to lower the overhead pressure on the auger. For the gravel a cover (hat) was added over the auger opening to reduce overhead pressure and eliminate auger binding. For the powdery materials (Portland cement, and other bulk materials) vibrators were added to eliminate rat-holing and bridging over the auger opening, and a vibration sequence was implemented in the control system to maintain continuous flow. For the weigh hopper a leveling routine was required to prevent materials from piling up under the auger discharges. All these corrections were discovered and implemented during testing and could not be predicted analytically during design. The hopper design and shape was driven by the packaging requirements for transportation and resulted in some design compromises regarding optimum hopper shape and flow characteristics.

\section{LESSONS LEARNED}

1. Could not flow damp or wet sand. The original design assumed the availability of dry sand which flows easily into the auger opening with gravity. But in field trials it was difficult to guarantee the dry sand, and damp/wet sand was often a problem. This was addressed in the upgrades phase of the project as discussed in the testing section.

2. Horsepower calculations must be proven empirically using full scale hardware and actual feedstock materials. Auger design is very difficult to be done 
analytically, so testing is very important in selecting/sizing the augers. We purchased a smaller motor for the WH based on analytical calculations, but needed to replace it with a motor three times its calculated size after testing the torque required for $\mathrm{WH}$ full of material.

3. Mechanical vibration can aid or hinder flow of materials. Vibrators help some materials like the powdery commodities to enhance the flow, but too much vibration can cause compaction of the materials and jamming of the auger tubes. So vibration must be fine-tuned and used sparingly. Also with multiple hoppers in contact with each other vibration of one hopper can lead to compaction of the material in the adjacent hoppers so vibration must be used in limited bursts to get the desired results.

4. Vibration and electromagnetic interference (EMI) creates noise on load cells. The entire machine depends on the accuracy of the load cells to measure the dispensed material. We added vibration isolators and adjusted the motor speed to slow down as we approached the target weight to reduce mechanical vibrations and improve accuracy. Also, we disabled vibration during measurement. Some EMI noise from other components like the air conditioner and power supplies in the control cabinet also contribute to noise on the load cells and special consideration was given to these to minimize the EMI noise.

\section{SYSTEM ENHANCEMENTS}

After delivery to the customer and field testing there were a number of lessons learned which lead to a number of upgrades being retrofitted to the system. Some of these include:

1. Adding screens to the hopper openings to prevent foreign object debris such as large rocks, plastic bags, etc. from entering the hoppers and jamming the augers.

2. Improved cover design for the auger motors to improve access for maintenance.

3. Weigh hopper side extensions to prevent material from overflowing. Improved clean out flanges for the augers for easier access to the back of the augers to clean and clear jams.

4. An enhanced air fluidizer system for the sand hoppers to allow the transfer of damp sand. A full size clear Lexan mockup is being built at KSC to study and solve the difficult problem of damp and transfer. The team is building a full scale Sand Hopper mock-up system consisting of a clear polycarbonate hopper, poly carbonate auger tube, auger motor/gearbox, pneumatic fluidizer, and control system.

\section{REFERENCES}


Mueller, R. P., Sibille, L., Hintze, P. E., Lippitt, T. C., Mantovani, J. G., Nugent, M. W., and Townsend, I. I. (2014) "Additive Construction using Basalt Regolith Fines.” ASCE Earth and Space 2014, 394-403.

Mueller, R. P., Fikes, John C., Case Michael P., Khoshnevis, B., Fiske, Michael R., Edmundson Jennifer E., Kelso, R., Romo, R., Andersen C. "Additive Construction with Mobile Emplacement (ACME)" IAC- 10/25/2017 